\title{
Linkage studies and deletion screening in choroideremia
}

\author{
A F Wright, R L Nussbaum, S S Bhattacharya, M Jay, J G Lesko, H J Evans, B Jay
}

\begin{abstract}
Fourteen families with choroideremia (TCD) have been examined for linkage to nine genetic markers located on the proximal long arm of the $X$ chromosome. Linkage to three markers (DXYS1, DXS72, $D X S 3$ ) located in Xq21 was found with a four point lod score of $8 \cdot 25$. No evidence of submicroscopic deletions was observed using DXS233 and DXS232, both thought to lie within about $1 \mathrm{Mb}$ of the TCD gene.
\end{abstract}

Choroideremia (McKusick No 30310; tapetochoroidal dystrophy, TCD) is a progressive, $\mathrm{X}$ linked degeneration of the choroid and retina. Onset is usually in the first or second decade in males, with pigmentary changes and choroidal atrophy, progressing to loss of central vision usually in the sixth decade. Females are generally asymptomatic although they usually show characteristic fundus changes, ranging from a minimal pigmentary disturbance to focal areas of loss of retinal pigment epithelium. Linkage was first reported by Nussbaum $e t a l^{1}$ between $T C D$ and the $D X Y S 1$ locus, located on the proximal long arm of the $\mathrm{X}$ chromosome at Xq13-q21. This finding was confirmed by Jay et al, ${ }^{2}$ Schwartz et al, ${ }^{3}$ and Sankila $e t$ $a l .{ }^{4}$ Other loci found to show significant evidence of linkage to $T C D$ include $D X Y S 12$ and $D X S 3,{ }^{45}$ both

MRC Human Genetics Unit and Department of Medicine, Western General Hospital, Crewe Road, Edinburgh EH4 2XU.

A F Wright, S S Bhattacharya", H J Evans

Howard Hughes Medical Institute and Department of Human Genetics, University of Pennsylvania, Philadelphia, PA 19104-6072, USA.

R L Nussbaum, J G Lesko

Department of Clinical Ophthalmology, University of London and Moorfields Eye Hospital, City Road, London EC1V 2PD.

M Jay, B Jay

Correspondence to Dr Wright.

${ }^{*}$ Present address: Department of Human Genetics, University of Newcastle upon Tyne.

Received for publication 19 October 1989

Revised version accepted for publication 7 February 1990 located in proximal Xq. Lesko et $a l^{5}$ carried out a multipoint linkage analysis of 12 TCD families using nine DNA probes and found significant evidence of linkage to five loci (PGK, DXYS1, DXS72, DXYS12, and $D X S 3$ ). They proposed a gene order putting $T C D$ proximal to $D X S 3$ with odds of $96: 1$ (DXS1DXYS1-TCD-DXS3-DXS17 or DXS1-TCD$D X Y S 1-D X S 3-D X S 17)$ in contrast to others ${ }^{6}$ who had suggested a distal location in a study of two TCD families.

Further support for a location close to DXYS1 has come from the study of TCD patients carrying microscopic and macroscopic deletions of this and neighbouring loci. ${ }^{7-9}$ The first report was by Rosenberg $\mathrm{et}^{\mathrm{al}} \mathrm{l}^{7}$ who reinvestigated a male carrying an interstitial deletion in Xq13-q21.3. This patient was severely mentally retarded with agenesis of the corpus callosum, cleft lip and palate, and on ophthalmological examination was found to have TCD. The DXYS1 locus was found to be deleted while DXS17 was present. Hodgson $e t a l^{8}$ also reported a cytogenetically visible deletion in subband $\mathrm{Xq} 21.1$ in a male with TCD, mental retardation, and minor dysmorphic features. Two probes were also deleted in this subject, at the DXYSI and DXS3 loci, respectively. Nussbaum et al found deletions in two further families in which TCD was associated with mental retardation and deafness, only one of which $(X L-62)$ showed a cytogenetically detectable deletion in Xq21, also associated with loss of DXYS1 and DXS72. The second family (XL-45) showed no visible deletion or loss of signal at the above loci. However, two clones (DXS232, DXS233) were isolated using the phenol enhanced reassociation technique ( $p E R T$ ) which were found to be deleted in this family. ${ }^{9}$ Finally, Cremers et $a l^{10}$ reported finding deletions in two out of eight unrelated classical TCD patients with probe plbD5 (DXS165), also located in Xq12-q21.3. We report here the results of further linkage studies in 14 TCD families using nine DNA probes and the results of deletion screening at the DXS232 and DXS233 loci.

\section{Methods}

Fourteen TCD families (C1-5, 9-12, 14-16, 20, 22), were ascertained at the Genetic Clinic, Moorfields Eye Hospital, London, and included in the study. The diagnosis of TCD in males and carrier females 
was made as described previously. ${ }^{2}$ Females over the age of 14 years showing no clinical evidence of carrier status were taken to be normal. ${ }^{2}$ DNA was extracted from whole blood by the method of Kunkel et al. ${ }^{11}$ The DNA was digested with restriction endonuclease ( 3 to 5 units $\mu \mathrm{g}^{-1} \mathrm{DNA}$ ), separated by electrophoresis in $0.8 \%$ agarose, and transferred to nylon filters by the method of Southern. ${ }^{12}$ The probes and their associated restriction fragment length polymorphisms are shown in table 1 . Probes were labelled by random priming and hybridisations carried out as described previously. ${ }^{5} 14$

Linkage analyses were carried out using the linkage programs described by Clayton ${ }^{15}$ (two point analyses) and the LINKMAP subroutine of LINKAGE ${ }^{16}$ (multipoint analysis). Approximate $\mathbf{9 0 \%}$ confidence limits were calculated by reducing the lod score at the maximum value of the recombination fraction by one unit. ${ }^{17}$

\section{Results}

LINKAGE ANALYSES

The results of two point linkage analyses using nine DNA probes are shown in table 2 . Three loci $(D X S 1$, $D X Y S 1, D X S 72)$ show no definite recombination with $T C D$ in these families. The strongest evidence for close linkage is between TCD and DXYSI with a lod score of $5 \cdot 16$ at zero recombination $(90 \%$ limits, $\theta=0-0 \cdot 10)$. The $D X S 1$ locus located more proximally (table 1) also shows no recombination (lod score 1.98), nor does the $D X S 72$ locus (lod score 1.97). With more distal probes (DXS17, DXS11, DXS178, $D X S 177)$ the recombination fractions $(\theta)$ are larger and the lod scores low, as is the case with the proximal $\mathrm{X}$ short arm marker, DXS14. The DXS3 locus has been reported to show significant evidence of linkage to $T C D$ at $\theta$ values of $0.04($ lod score 12.32$)$ and 0.05 (lod score 5.81) respectively. ${ }^{4}{ }^{5} \mathrm{We}$ found a maximum likelihood value of $\theta$ at $0 \cdot 11$ at a lod score of $1 \cdot 62$. Since recombination has been observed with $D X S 3$, a multipoint analysis was run with TCD, DXYS1, $D X S 72$, and $D X S 3$, using LINKMAP. ${ }^{16}$ The result is shown in table 3 . The most likely order, with $T C D$ proximal to $D X Y S 1$ and $D X S 3$ is only $4 \cdot 4$ fold more

Table 3 Results of a multipoint linkage analysis of TCD and three loci (DXYS1, DXS72, DXS3), to try and establish the most likely order of these loci. The results were obtained with the program LINKMAP. Location scores, lod scores $(z)$, and odds were obtained as described by Lathrop et al. ${ }^{16}$

\begin{tabular}{ccc}
\hline Order & $\begin{array}{l}\text { Location } \\
\text { score }(\mathrm{z})\end{array}$ & Odds \\
\hline A $T C D-D X S 72-D X Y S 1-D X S 3$ & $37 \cdot 97(8 \cdot 25)$ & A $v$ D $4 \cdot 4: 1$ \\
B DXS72-TCD-DXYSI-DXS3 & $37 \cdot 97(8 \cdot 25)$ & B $v$ D $4 \cdot 4: 1$ \\
C DXS72-DXYSI-TCD-DXS3 & $36 \cdot 41(7 \cdot 92)$ & C $v$ B $2 \cdot 2: 1$ \\
D DXS72-DXYS1-DXS3-TCD & $35 \cdot 00(7 \cdot 61)$ & D $v$ C $2 \cdot 0: 1$ \\
\hline
\end{tabular}

Table 1 Summary of the probes used in this investigation with their locations and associated polymorphisms. Nomenclature and assignments as in Mandel et al. ${ }^{13}$

\begin{tabular}{|c|c|c|c|c|c|}
\hline Locus & Probe & Region & $\begin{array}{l}\text { RFLP } \\
\text { enzyme }\end{array}$ & Alleles $(\mathbf{k b})$ & $\begin{array}{c}\text { Allele } \\
\text { frequencies }\end{array}$ \\
\hline$D X S 14$ & p58-1 & Xpl1.21 & $M s p I$ & $4 \cdot 0 / 2 \cdot 5$ & $0.65 / 0.35$ \\
\hline$D X S I$ & p8 & $\mathrm{Xq} 11.2-\mathrm{q} 12$ & TaqI & $15 \cdot 0 / 9 \cdot 0$ & $0 \cdot 84 / 0 \cdot 16$ \\
\hline$D X S 72$ & $\mathrm{pX} 65 \mathrm{H} 7$ & $\mathrm{Xq} 21.1$ & HindIII & $7 \cdot 2 / 0 \cdot 7$ & $0.45 / 0.55$ \\
\hline$D \times S 232$ & pJL68 & $\mathrm{Xq} 21.1-\mathrm{q} 21.2$ & - & - & - \\
\hline$D X S 233$ & pJL8 & $\mathrm{Xq} 21.1-\mathrm{q} 21.2$ & - & - & - \\
\hline DXS276 & pJL77 & $\mathrm{Xq} 21.1$ & - & - & - \\
\hline DXYSI & pDP34 & $\mathrm{Xq} 21.31$ & TaqI & $11 \cdot 0 / 12 \cdot 0$ & $0 \cdot 60 / 0 \cdot 40$ \\
\hline \multirow[t]{2}{*}{$D \times S 3$} & pl9-2 & $\mathrm{Xq} 21.3$ & $M s p I$ & $11 \cdot 0 / 4 \cdot 3$ & $0 \cdot 79 / 0 \cdot 21$ \\
\hline & & & TaqI & $2 \cdot 95,2 \cdot 15 / 5 \cdot 1$ & $0.62 / 0.38$ \\
\hline$D X S 17$ & $\mathrm{~S} 21, \mathrm{~S} 9$ & $\mathrm{Xq} 22$ & $\operatorname{Taq} \mathbf{I}$ & $2 \cdot 2 / 2 \cdot 0$ & $0.65 / 0.35$ \\
\hline DXS178 & p212/9 & $\mathrm{Xq} 21.33-\mathrm{q} 22$ & TaqI & $3 \cdot 2 / 1 \cdot 8$ & $0 \cdot 70 / 0 \cdot 30$ \\
\hline DXS11 & p22-33 & $\mathrm{Xq} 24-\mathrm{q} 25$ & TaqI & $11 \cdot 0 / 20 \cdot 0$ & $0.83 / 0.17$ \\
\hline$D X S I 77$ & p).2.7 & $\mathrm{Xq} 26$ & EcoRI & $7 \cdot 0 / 6 \cdot 0$ & $0 \cdot 80 / 0 \cdot 20$ \\
\hline
\end{tabular}

Table 2 Table of lod scores between TCD and the markers shown, with the maximum likelihood values of the recombination fraction $(\theta \max )$ and the corresponding lod scores (lodmax).

\begin{tabular}{|c|c|c|c|c|c|c|c|c|c|c|}
\hline \multirow[b]{2}{*}{ Locus } & \multicolumn{8}{|c|}{ Recombination fraction } & \multirow[b]{2}{*}{ Lodmax } & \multirow[b]{2}{*}{$\theta \max$} \\
\hline & $0 \cdot 00$ & 0.05 & $0 \cdot 10$ & $0 \cdot 15$ & $0 \cdot 20$ & $0 \cdot 25$ & $0 \cdot 30$ & $0 \cdot 40$ & & \\
\hline DXSI4 & $-x$ & $-1 \cdot 78$ & -0.80 & -0.34 & -0.08 & 0.05 & 0.11 & $0 \cdot 10$ & $0 \cdot 12$ & 0.34 \\
\hline IDXSI & 1.98 & 1.82 & 1.65 & $1 \cdot 48$ & $1 \cdot 30$ & $1 \cdot 11$ & 0.91 & $0 \cdot 48$ & 1.98 & 0.00 \\
\hline DXS72 & 1.97 & $1 \cdot 79$ & $1 \cdot 60$ & $1 \cdot 40$ & $1 \cdot 19$ & 0.97 & 0.75 & 0.28 & 1.97 & 0.00 \\
\hline DXYSI & $5 \cdot 16$ & $4 \cdot 68$ & $4 \cdot 19$ & $3 \cdot 68$ & $3 \cdot 14$ & $2 \cdot 60$ & $2 \cdot 05$ & 0.97 & $5 \cdot 16$ & 0.00 \\
\hline $10 \times S 3$ & $-x$ & $1 \cdot 38$ & $1 \cdot 61$ & 1.58 & $1 \cdot 44$ & $1 \cdot 25$ & $1 \cdot 03$ & 0.56 & $1 \cdot 62$ & $0 \cdot 11$ \\
\hline DXS17 & $-x$ & -0.56 & 0.33 & $0 \cdot 70$ & 0.85 & 0.86 & 0.77 & $0 \cdot 38$ & 0.87 & 0.23 \\
\hline DXSS11 & $-x$ & $1 \cdot 42$ & $1 \cdot 49$ & $1 \cdot 42$ & $1 \cdot 28$ & $1 \cdot 10$ & 0.88 & 0.40 & $1 \cdot 49$ & 0.09 \\
\hline 1$) X S 178$ & $-x$ & $0 \cdot 05$ & 0.91 & $1 \cdot 16$ & $1 \cdot 19$ & $1 \cdot 11$ & 0.94 & 0.46 & $1 \cdot 20$ & $0 \cdot 19$ \\
\hline I)XS177 & $-x$ & $-0 \cdot 23$ & 0.02 & 0.13 & $0 \cdot 19$ & 0.21 & $0 \cdot 20$ & $0 \cdot 14$ & $0 \cdot 21$ & $0 \cdot 27$ \\
\hline
\end{tabular}


likely than that with the disease locus located distal to $D X S 3$. The four point lod scores for the most likely orders (A, B in table 3 ) with $T C D$ proximal to DXYS1 are 8.25 , providing highly significant evidence of linkage. These results assume that the three marker loci are each separated by a recombination fraction of 0.02 in the order DXS72-DXYS1DXS3. 518

\section{DELETION SCREENING}

None of the nine probes examined was found to be deleted in any of these families. Affected family members were screened with three additional probes isolated by Nussbaum et a $\varphi^{\prime}$ : pJL8 (DXS233), pJL68 (DXS232), and pJL77(DXS276). No evidence of deletion or rearrangement was found with these three loci by Southern analysis of patient's DNA digested and separated by conventional electrophoresis. A rare restriction fragment length polymorphism was seen for DXS233 with the enzyme PvuII in one family (alleles $5 \mathrm{~kb}$ and $9 \mathrm{~kb}$ ), but no other variants were identified.

\section{Discussion}

These linkage results are consistent with those reported previously, with $T C D$ tightly linked to $D X Y S 1$ (Xq21.31) and neighbouring probes DXS72 and DXS3 (four point lod score $8 \cdot 25$ ). The DXS1 locus located more proximally in Xq11-q13 shows no definite recombination either (lod score 1.98), consistent with the possibility that this proximal, centromeric region shows relatively low rates of recombination. More distally located probes $(D X S 17$, DXS178, DXS11, DXS177) show higher recombination rates with the $T C D$ locus, consistent with a localisation for $T C D$ in the Xq21.2-q21.3 region. ${ }^{1} 18$

A number of microscopic and submicroscopic deletions have been identified in patients in whom TCD forms part of more complex syndromes, including mental retardation, deafness, and cleft lip and palate. ${ }^{7-9}$ More recently, microdeletions were found in two out of eight unrelated TCD males with no other clinical abnormalities, ${ }^{10}$ using probe plbD5 (DXS165). We therefore wished to exclude the possibility of similar microdeletions in this sample of patients from classical TCD families using three loci, two of which (DXS232, DXS233) lie within a deletion (XL-45) containing the TCD locus which is estimated to be $<1250 \mathrm{~kb}$ in size. ${ }^{9}$ The results show that there is no evidence of microdeletions detectable with the above probes. We were also unable to detect any submicroscopic deletions in these families with plbD5 (DXS165), although one small (120 to $150 \mathrm{~kb}$ ) deletion was found in family C3 using two clones located distal to plbD5 (F P M Cremers et al, submitted). Merry $e t a^{19}$ also failed to find deletions in any of 42 unrelated TCD probands using probe plbD5, but detected a translocation breakpoint in a woman with choroideremia and a de novo $X ; 13$ translocation.

This work was generously supported by grants to AFW, SSB, and RLN from the National Retinitis Pigmentosa Foundation Fighting Blindness and George Gund Foundation. Other support came from the Howard Hughes Medical Institute (RLN, JGL) and NIHRO1-EY-06566. We are grateful to J Ott for supplying the LINKAGE programs and to Drs G Bruns, D Page, B Schmeckpeper, K E Davies, and L M Kunkel for providing probes. We would also like to thank the families for their participation.

1 Nussbaum RL, Lewis RA, Lesko JG, Ferrell R. Choroideremia is linked to the restriction fragment length polymorphism DXYS1 at Xq13-21. Am F Hum Genet 1985;37:473-81.

2 Jay M, Wright AF, Clayton JF, et al. A genetic linkage study of choroideremia. Ophthalmic Paediatr Genet 1986;7:201-4.

3 Schwartz M, Rosenberg T, Niebuhr E, et al. Choroideremia: further evidence for assignment of the choroideremia locus to Xq13-Xq21. Hum Genet 1986;74:449-52.

4 Sankila EM, de la Chapelle A, Karna J, Forsius H, Frants R, Eriksson A. Choroideremia: close linkage to DXYS1 and DXYS12 demonstrated by segregation analysis and historical genealogical evidence. Clin Genet 1987;31:315-22.

5 Lesko JG, Lewis RA, Nussbaum RL. Multipoint linkage analysis of loci in the proximal long arm of the human $\mathrm{X}$ chromosome: application to mapping the choroideremia locus. Am $\mathcal{F} \mathrm{Hum}$ Genet 1987;40:303-11.

$6 \mathrm{Gal} \mathrm{A,} \mathrm{Brunsmann} \mathrm{F,} \mathrm{Hokenkamp} \mathrm{D,} \mathrm{et} \mathrm{al.} \mathrm{Choroideremia-locus}$ maps between DXS3 and DXS11 on Xq. Hum Genet 1986;73: 123-6.

7 Rosenberg T, Schwartz M, Niebuhr E, et al. Choroideremia in interstitial deletion of the $\mathrm{X}$ chromosome. Ophthalmic Paediat Genet 1986;7:205-10.

8 Hodgson SV, Robertson ME, Fear CN, et al. Prenatal diagnosis of X-linked choroideremia with mental retardation, associated with a cytologically detectable $\mathrm{X}$-chromosome deletion. Hum Genet 1987;75:286-90.

9 Nussbaum RL, Lesko JG, Lewis RA, Ledbetter SA, Ledbetter DH. Isolation of anonymous DNA sequences from within a submicroscopic $X$ chromosomal deletion in a patient with choroideremia, deafness and mental retardation. Proc Natl Acad Sci USA 1987;84:6521-5.

10 Cremers FPM, Brunsmann F, Van de Pol DJR, et al. Deletion of the DXS165 locus in patients with classical choroideremia. Clin Genet 1987;32:421-3.

11 Kunkel LM, Tantravahi U, Eisenhard M, Latt SA. Regional localisation on the human X of DNA segments cloned from flow sorted chromosomes. Nucleic Acids Res 1982;10:1557-8.

12 Southern EM. Detection of specific sequences among DNA fragments separated by gel electrophoresis. F Mol Biol 1975; 113:237-51.

13 Mandel JL, Willard HF, Nussbaum RL, Romeo G, Puck JM Davies KE. Report of the committee on the genetic constitution of the X chromosome. Cytogenet Cell Genet 1989;51:384-437.

14 Wright AF, Bhattacharya SS, Clayton JF, et al. Linkage relationships between $\mathrm{X}$-linked retinitis pigmentosa and nine short-arm markers: exclusion of the disease locus from Xp21 and localisation to between DXS7 and DXS14. Am $\mathcal{F} \mathrm{Hum}$ Genet 1987;41:635-44.

15 Clayton JF. A multipoint linkage analysis program for X-linked disorders, with the example of Duchenne muscular dystrophy and seven DNA probes. Hum Genet 1986;73:68-72.

16 Lathrop GM, Lalouel JM, Julier C, Ott J. Strategies for multilocus linkage analysis in humans. Proc Natl Acad Sci USA 1984;81:3443-6.

17 Conneally PM, Edwards JH, Kidd KK, et al. Report of the committee on methods of linkage analysis and reporting. HGM8. Cytogenet Cell Genet 1985;40:356-9.

18 Cremers FPM, Van de Pol DJR, Diergaarde PJ, et al. Physica fine mapping of the choroideremia locus using $\mathrm{Xq} 21$ deletions associated with complex syndromes. Genomics 1989;4:41-6.

19 Merry DE, Lesko JG, Sosnoski DM, et al. Choroideremia and deafness with stapes fixation: a contiguous gene deletion syndrome in Xq21. Am F Hum Genet 1989;45:530-40. 